\title{
College faculty support for grade 7-12 teaching careers: survey results and comparisons to student perceptions
}

\author{
Savannah L. Logan ${ }^{1}$, Jared B. Breakall ${ }^{1}$, Richard L. Pearson III ${ }^{1,2}$, and Wendy K. Adams ${ }^{1}$ \\ ${ }^{1}$ Department of Physics, Colorado School of Mines, 1500 Illinois Street, Golden, CO 80401 \\ ${ }^{2}$ Physical Sciences Department, Embry-Riddle Aeronautical University, 1 Aerospace Boulevard, Daytona \\ Beach, FL 32114
}

The United States is facing a critical shortage of grade 7-12 teachers in the STEM disciplines, particularly in physics, chemistry, and mathematics. Faculty members play a major role in their students' career choices, and faculty members' perceptions of the profession may determine whether students choose to pursue teaching. To this end, we developed two surveys to measure student and faculty perceptions of grade 7-12 teaching. We found that both groups hold many incorrect beliefs about teaching careers. Furthermore, we found that faculty members believe they are quite supportive of future teachers, while students perceive that they are less supportive. Our findings highlight the need for both faculty members and students to be informed about the benefits of careers in grade 7-12 teaching. Additionally, our results suggest that faculty members should work to dispel their internal biases surrounding the teaching profession, which may inadvertently drive students away from grade 7-12 teaching. 


\section{INTRODUCTION}

The United States is facing a critical shortage of grade 712 STEM (science, technology, engineering, and mathematics) teachers [1], with particularly worrying deficits in physics, chemistry, and mathematics [2]. This shortage has an alarming impact on the number of STEM majors at post-secondary institutions; high school students whose teachers do not have degrees in their content area are far less likely to choose to major in STEM disciplines in college, and are even less likely to choose to attend college at all [3]. Furthermore, roughly half of students who intend to major in a STEM discipline leave their field before finishing their degree [4], likely due in large part to inadequate preparation at the K-12 level [5]. Attrition in STEM fields at the college level, compounded with widespread deficiencies in secondary preparation in science and mathematics, has had a highly detrimental effect on the scientific and technological workforce in the US. This ultimately harms the nation's competitiveness in global technological industries and decreases the scientific literacy of the general population.

To assist faculty members who are working to address the national teacher shortage and the declining number of postsecondary STEM majors [6], we must examine the complex and varied reasons that college STEM majors choose not to pursue middle and high school teaching careers. A recent report by the American Physical Society found that roughly half of STEM majors have some level of interest in becoming a grade 7-12 teacher [7]. However, the majority of these interested students ultimately choose not to pursue teaching as a career [8]. Recent findings suggest that this gap may be in part the result of inaccurate perceptions of teaching careers among both college students and faculty members [9].

As is apparent to many experienced faculty members, college professors and advisors (both formal and informal) have a large impact on the career choices of their students [10]. If college faculty members communicate inaccurate information and negative misperceptions of teaching careers to their students, students will be far less likely to choose to pursue the teaching profession. To examine the perceptions and advising practices of faculty members with regards to teaching careers, we developed two instruments, the Perceptions of Teaching as a Profession (PTaP) survey for students and the Perceptions of Teaching as a Profession for Higher Education (PTaP.HE) survey for faculty and advisors. We have collected data from over 2,000 students and over 500 faculty members at universities across the United States, and we conducted additional student and faculty focus groups and/or interviews at six of those data collection sites.

In this paper we will show evidence that faculty member perceptions of teaching careers differ significantly from the perceptions of students who plan to become teachers. Faculty members tend to show less respect for the profession and believe it would be far less enjoyable than students perceive that it would be. Both students and faculty members had poor knowledge of facts about teaching careers, including salaries, stability, and benefits. Faculty members also believe that they are more supportive of teaching careers than students perceive them to be. In addition, this work highlights the perceptive nature of students when interacting with their advisors; if advisors have negative misperceptions about a career path, students perceive their negative attitudes even if they are never explicitly stated. These results show that advising and support for future teachers would be improved if faculty members became more knowledgeable about teaching careers and developed more respect for teaching as a profession.

This work was conducted as part of the Get the Facts Out Project, an NSF-funded longitudinal study aimed at correcting misperceptions about the teaching profession and changing the conversation around STEM teacher recruitment through the development of research-based, user-tested recruiting resources.

\section{METHODS}

\section{A. Research questions}

Here, we seek to answer two questions:

(1) What similarities and differences do faculty members and students have in their perceptions of teaching as a career?

(2) What similarities and differences exist between faculty and student perceptions of advising and support for teaching careers?

These two questions will provide important insights into how faculty can better support future teachers by changing their perceptions, attitudes, and advising strategies. The second question will also highlight areas where faculty members might perceive that they are more supportive than students feel that they are.

\section{B. Survey design}

The PTaP and PTaP.HE were developed to measure perceptions of grade 7-12 teaching careers among college students and faculty members, respectively. Each instrument consists mainly of five-point Likert-scale statements with a small number of selected response items. Statements on both instruments range from personal enjoyment statements ("I think I would enjoy grade 7-12 teaching day-to-day") to factual statements ("Grade 7-12 teachers have competitive benefits compared to other careers") to advising and support statements ("I regularly discuss grade 7-12 math or science teaching as a career option with students"). Both instruments were developed using standard guidelines as 
outlined in Adams et. al [11]. The detailed development and validation of both instruments, which included student and faculty interviews, will be described in forthcoming papers.

\section{Data collection and analysis}

Data was collected from 44 institutions of higher education across the United States. Altogether, over 500 faculty members and over 2000 students at these institutions responded to our surveys. Institutions were self-selected and varied widely in size, selectivity, type (private vs. public), demographics, and geographic locations. Total enrollments ranged from under 1,300 undergraduate students to over 58,000 . For a complete list of participating institutions, please see [12].

To analyze the data, each statement on the PTaP and PTaP.HE is given a percent favorable or "expert-like" score, which represents the percentage of respondents whose answer agrees with the response of an expert. In many cases, the statements are fact-based, and the expert-like response is simply the correct answer. For example, the statement, "On average, grade 7-12 teachers can retire before age 60 and not have to work after retirement" is measurably true and should be agreed or strongly agreed with in order to receive an expert-like score.

To aid in the interpretation of the PTaP and PTaP.HE, we conducted an exploratory factor analysis for each instrument to determine underlying factors, similar to the analysis performed on the CLASS [13]. This resulted in 11 empirical categories for the PTaP and 10 empirical categories for the PTaP.HE; all are listed below in Table 1. Each factor is given a score representing the average percent-favorable score of every statement within that factor.

Using the scores of individual statements and factors, we can better understand how faculty members and students view the teaching profession and where their knowledge is either sufficient or lacking. We can also compare the scores of students and faculty members on analogous statements on the PTaP and PTaP.HE to understand where perceptions of the career (and perceptions of support for the career) might differ. An analysis based on faculty type was also conducted and will be described in a forthcoming paper.

TABLE 1: PTaP and PTaP.HE empirical categories as determined by factor analysis. The number of statements in each category is listed in parenthesis. For a complete list of the statements by category, see [15].

\begin{tabular}{ll}
\hline \hline \multicolumn{1}{c}{ PTaP } & \multicolumn{1}{c}{ PTaP.HE } \\
\hline 1. Personal Enjoyment (7) & 1. Facts About Teaching (8) \\
2. As a Career Choice (9) & 2. Salary Accuracy (3) \\
3. Others Support me & 3. Teaching is a Good \\
Teaching (6) & Career (6) \\
4. My Department Values and & 4. Teacher Satisfaction (5) \\
Encourages Teaching (5) & \\
5. My Department Supports & 5. Respects the Profession \\
Me Teaching (4) & (6)
\end{tabular}

6. Employee Benefits and

Stability (3)

7. Teaching is Scientific (5)

8. Nurturer (5)

9. All Students Can Learn (3)

10. I Would If... (4)

11. Back Up Plan (4)

\section{RESULTS: FACULTY AND STUDENT PERCEPTIONS OF TEACHING AS A CAREER}

Faculty members and students differ considerably in their views of teaching as a profession. While both students and faculty members hold many incorrect beliefs about objective facts about teaching, such as benefits and stability, we also found evidence that faculty members are less likely than students to think that teaching would be enjoyable, and they are much less likely than students to take pride in teaching as a career.

\section{A. Pride in teaching careers}

To measure pride in teaching careers, we focused on two analogous statements on the PTaP and the PTaP.HE. On the PTaP, we asked students whether they agreed or disagreed that they would be proud to tell others that they were a grade 7-12 teacher; similarly, we asked faculty members whether they agreed or disagreed with, "I would be just as proud to tell people that I am a grade 7-12 teacher as I am to tell them that I am a faculty member at my current institution". Among students who indicated that they plan to pursue teacher certification (e.g. they are highly likely to become teachers), an encouraging $81 \%$ indicated that they would be proud to tell others. However, only $37 \%$ of faculty answered affirmatively, indicating a large discrepancy in their respect for the two professions. Faculty members could be much more effective at recruiting teachers if they worked to see the value and pride in teaching careers.

\section{B. Perceptions of enjoyment}

Along with measurements of pride in teaching careers, we included parallel statements on the PTaP and PTaP.HE to measure whether students and faculty members perceive teaching to be an enjoyable career day-to-day. Notably, there is data suggesting that most teachers do find their careers enjoyable [14]. Among students who indicated that they are planning to pursue teacher certification, $84 \%$ agreed or strongly agreed that teaching would be enjoyable day-to-day. An analogous statement on the PTaP.HE read, "I think grade 7-12 math or science teaching would be an enjoyable career day-to-day." Here, only $55 \%$ of faculty members agreed or strongly agreed. However, $81 \%$ of faculty members claimed they would be comfortable with their strongest student becoming a grade 7-12 teacher. These two results suggest dissonance in faculty perceptions; why would a significant 
percentage of faculty members be comfortable with their students pursuing a career that they believe is not enjoyable? This situation highlights a key area for faculty members to improve; while many think they are supportive of any career choice, their internal beliefs about certain careers are negatively biased. We believe this discourages students from pursuing those careers, even if the negative biases are never explicitly stated.

\section{Knowledge of facts about teaching careers}

Our factor analysis of the PTaP and PTaP.HE identified several categories that were centered on facts about teaching careers. These included facts about retirement benefits, stability, salaries compared to other professions, and more. (For a complete list of questions and categories, please contact the authors or see [15]). On the PTaP, one fact-based category emerged called "Employee Benefits and Stability," which contained three statements related to benefits, retirement, and stability. Only about $25 \%$ of students who wanted to become teachers agreed with the experts in this category. This number is surprisingly low considering that these students plan to go into the profession, and the authors suspect that their answers came largely from negative representations of teaching in the media. For students who did not want to become teachers, the agreement with experts was closer to $15 \%$. To be clear, the majority of both groups of students perceived the benefits and stability of teaching careers to be much worse than they actually are.

Results from our faculty-facing instrument were similarly non-expert-like regarding fact-based statements about teaching, which may be part of the reason why students have such limited knowledge of teaching career facts. In the PTaP.HE, our factor analysis resulted in two fact-based categories, one of which we simply called "Facts About Teaching." This category included eight statements related to benefits, retirement, stability, teacher retention, interest in teaching among students, and teachers' relationships with their colleagues. Similar to our student results, most faculty members underestimated the positive aspects of teaching careers. For example, almost $62 \%$ of faculty agreed or strongly agreed with, "Teaching pays a lot less than most other careers a student can get with the same degree." However, this is a statement that is objectively not true. Starting teacher salaries are comparable to the starting salaries in other STEM professions, and mid-career teacher salaries typically range between $\$ 60,000$ and $\$ 100,000$ [14].

Furthermore, $82 \%$ of faculty members underestimated teacher retention, and about $70 \%$ of faculty members underestimated retirement benefits for teachers. Overall, less than $36 \%$ of faculty members who took our survey had expert-like responses in the "Facts About Teaching" category. If faculty advisors are unsure of the facts about teaching careers, or, even worse, communicate negative misperceptions about teaching careers, it is likely that they will turn their students away from the profession. At a minimum, they will not be able to accurately advise their students. Misinformation is likely to be a major reason that students avoid teaching careers, exacerbating the nationwide teacher shortage that we see today.

\section{RESULTS: FACULTY AND STUDENT PERCEPTIONS OF ADVISING AND SUPPORT}

Similar to our results regarding perceptions of teaching careers, we found evidence that students and faculty differ in their perceived support for teaching careers. In general, faculty tend to overestimate their support for teaching when compared to student perceptions of their support. Additionally, faculty members tend to favor other career options over grade 7-12 teaching for their students.

\section{A. Career support}

Regarding support for teaching careers in comparison to other options, we found disparities between the perceptions of faculty members and students. One statement on the PTaP reads: "If I told my advisor I wanted to be a grade 7-12 teacher, s/he would encourage me." $71 \%$ of student respondents agreed or strongly agreed with this statement. While it is encouraging that the majority of students were in agreement with this statement, it is worth emphasizing that almost $30 \%$ of surveyed students either were unsure or thought their advisor would not encourage them to become a grade 7-12 teacher, even after they had expressed interest.

We included a related set of analogous statements on the PTaP.HE: whether faculty members would be comfortable with their strongest student becoming a grade 7-12 teacher, going into industry, or going to graduate school. $81 \%$ of faculty members agreed or strongly agreed with the statement, "I would feel comfortable if one of my strongest students became a grade 7-12 math or science teacher." This, as noted above, is $10 \%$ higher than student perceptions of their encouragement. On the other hand, $86 \%$ of faculty members agreed or strongly agreed with, "I would feel comfortable if one of my strongest students went into industry", and $96 \%$ of faculty members, almost all of our respondents, agreed or strongly agreed with 'I would feel comfortable if one of my strongest students went to graduate school". Students are perceptive, and it is likely that they will notice the subtle cues that their advisors give them. If advisors have a preference for their students going to graduate school, their students will probably notice this preference even if it is never explicitly stated.

\section{B. Advising practices with regards to teaching careers}

In our factor analysis of the PTaP.HE, a category emerged called "Advising and Support." This category included statements such as "I regularly discuss grade 7-12 teaching as a career option with students" and "Students are encouraged to consider grade 7-12 math or science teaching by other faculty in my department." It also included an 
estimate of the percentage of students who have some level of interest in becoming a teacher. Nationally, faculty members scored almost $66 \%$ favorable in this category. A somewhat analogous category emerged in the PTaP, called "My Department Values and Encourages Teaching." Statements in this category included "My department would be proud if I became a grade 7-12 teacher" and "Professors in my department discuss teaching as a career option with students." Nationally, students scored just under $47 \%$ favorable in this category. This means that these two analogous advising and support categories had an almost 20 percentage point difference between the perceptions of faculty and the perceptions of students. This indicates a disconnect between how supportive faculty members think they are and how supportive students perceive them to be. The authors believe this may be due in part to students reading body language and other subtle cues when discussing career options with their advisors. Faculty members may not explicitly discourage teaching, but they might subconsciously dissuade students by hesitating or making disparaging remarks when discussing teaching careers.

\section{CONCLUSIONS, LIMITATIONS, AND FUTURE WORK}

\section{A. Conclusions}

Many physics faculty members across the United States are working to address the critical shortage of qualified U.S. STEM teachers [16]. This issue must be addressed in order to increase the number of university STEM graduates, increase broad scientific literacy in the general population, and retain the nation's competitiveness in global scientific and technological industries. Students look to faculty advisors as a major source of advice when choosing a career path. This work provides evidence that faculty members must be properly informed about STEM teaching careers in order to help abate the nationwide teacher shortage. In addition, to prevent communication of subtle and subconscious cues that discourage students from pursuing the profession, faculty members must develop a genuine respect for the profession.

This study also provides evidence that faculty member perceptions of teaching careers tend to be more negative than the perceptions of students who want to become teachers, which severely hampers teacher recruitment efforts. Additional evidence suggests that faculty members tend to have less respect for the profession as indicated by statements about pride in being a grade 7-12 teacher, and faculty members believe teaching would be less enjoyable than students perceive that it would be. Both students and faculty members have poor knowledge of facts about teaching careers, including salaries, stability, and benefits.

Importantly, faculty members believe that they are more supportive of teaching careers than students perceive them to be. There was a nearly 20 percentage point difference between faculty member and student perceptions in categories related to support for teaching careers, and faculty members are more likely to encourage their students to go into industry or graduate school than to go into teaching.

These results show that if faculty members want to support their students' interests, they should educate themselves about teaching careers and develop more respect for teaching as a profession. As a starting point, we recommend that faculty members visit www.GettheFactsOut.org to learn more about the teaching profession and to find recommendations and resources for sharing the facts with students. Evidence suggests that correcting negative misperceptions about teaching careers among faculty members will have a major impact on teacher recruitment efforts [9]. In order to correct the nationwide deficit in grade 7-12 STEM teachers, this should be a central goal of all STEM departments.

\section{B. Limitations}

All institutions of higher education enrolled in this study were self-selected; therefore, it is likely that our data is skewed toward institutions that already have an investment in STEM teacher preparation. Participation in the surveys was also optional for both students and faculty members (although some institutions offered small incentives to participants, such as extra credit in courses). This means that our data within each institution could also be biased toward those who already have some level of interest in teaching or teacher preparation. Because of these factors, it is possible that the perceptions of teaching described in this study are slightly more positive than average perceptions at colleges across the United States.

\section{Future work}

The Get the Facts Out project is a five-year longitudinal study. We plan to collect data from all institutions described in this study each year for an additional four years, and we will also encourage each site to implement strategies that have been proven to improve perceptions of the teaching profession. We hope to see gains in expert-like perceptions of the teaching profession among faculty members and students as the Get the Facts Out project progresses. We will also monitor the number of students enrolled in teacher certification programs at each site, and we expect that these numbers will increase as local perceptions improve.

\section{ACKNOWLEDGMENTS}

The authors would like to thank everyone involved in the Get the Facts Out project. This material is based upon work supported by the National Science Foundation under Grant Nos. 1821710 \& 1821462 . Any opinions, findings, and conclusions or recommendations expressed in this material are those of the authors and do not necessarily reflect the views of NSF. 
[1] F. Cross, Teacher Shortage Areas Nationwide Listing 19901991 through 2017-2018 (U.S. Department of Education, Washington, DC, 2017). Retrieved May 22, 2020 from https://www2.ed.gov/about/offices/list/ope/pol/ateachers hortageareasreport2017-18.pdf.

[2] Aragon, S. (2016). Teacher Shortages: What We Know. Teacher Shortage Series. Education Commission of the States, (May), 1-12. Retrieved May 22, 2020 from https://eric.ed.gov/?id=ED565893.

[3] Lee, S. W., \& Mamerow, G. (2019). Understanding the role cumulative exposure to highly qualified science teachers plays in students' educational pathways. Journal of Research in Science Teaching, 56(10), 1362-1383. https://doi.org/10.1002/tea.21558.

[4] Chen, X. and Solder, M. (2013). STEM Attrition: College Students' Paths Into and Out of STEM Fields (NCES 2014-001) (National Center for Education Statistics, U.S. Department of Education, Washington, DC 2013). Retrieved May 22, 2020 from https://nces.ed.gov/pubs2014/2014001rev.pdf.

[5] E. Seymour and N. M. Hewitt, Talking about Leaving: Why Undergraduates Leave the Sciences. Westview Press, 1997.

[6] STEM Education: Preparing for the Jobs of the Future. U.S. $\quad$ Congress Joint Economic Committee (2012). Retrieved May 22, $2020 \quad$ from https://www.jec.senate.gov/public/_cache/files/6aaa7elf -9586-47be-82e7-326f47658320/stem-education--preparing-for-the-jobs-of-the-future-pdf.

[7] M. Marder, R. C. Brown, and M. Plisch, Recruiting Teachers in High-Needs STEM Fields: A Survey of Current Majors and Recent STEM Graduates, A Report for the American Physical Society Panel on Public Affairs (American Physical Society, College Park, MD, 2017).

[8] J. Hill and C. Owens, Education and Certification Qualifications of Departmentalized Public High SchoolLevel Teachers of Selected Subjects: Evidence from the 2011-12 Schools and Staffing Survey (NCES 2015-814) (National Center for Education Statistics, U.S. Department of Education, Washington, DC, 2015).

[9] W.K. Adams, A new survey uncovers strong misperceptions about the teaching profession. What can we do to get the facts out? APS Forum on Education Fall 2017 Newsletter (2017).

[10] Major Influence: Where Students Get Valued Advice on What to Study in College. Strada Education Network and Gallup, Inc. (2017) Retrieved June 4, 2020 from https://www.insidehighered.com/sites/default/server_fil es/files/Gallup-Strada_Education_Network-MajorInfluence\%20EMBARGOED.PDF

[11] Adams, Wendy K., \& Wieman, C. E. (2011). Development and validation of instruments to measure learning of expert-like thinking. International Journal of Science Education, 33(9), 1289-1312 https://doi.org/10.1080/09500693.2010.512369
[12] A complete listing of all the survey sites can be found at https://getthefactsout.org/gfo-community. Retrieved August 3, 2020.

[13] Adams, W. K., Perkins, K. K., Podolefsky, N. S., Dubson, M., Finkelstein, N. D., \& Wieman, C. E. (2006). A New instrument for measuring student beliefs about physics and learning physics: The Colorado Learning Attitudes about Science Survey. Physical Review Special Topics - Physics Education Research, 2(1), 1-14. https://doi.org/10.1103/PhysRevSTPER.2.010101

[14] Mulvey, P. \& Pold, J. Physics Bachelors: Initial Employment Data from the degree recipient follow-up survey for the classes of 2013 and 2014 (American Institute of Physics Statistical Research Center, 2017).

[15] See www.getthefactsout.org/perceptions-surveys-ptapand-ptaphe. Retrieved May 22, 2020.

[16] See https://www.phystec.org. Retrieved June 4, 2020. 